\title{
Tissue hyperosmolality and brain edema in cerebral contusion
}

\author{
Tatsuro Kawamata, M.D., Tatsuro Mori, M.D., Shoshi Sato, M.D., AND Yoichi \\ KATAYAMA, M.D. \\ Department of Neurological Surgery, Nihon University School of Medicine, Tokyo, Japan
}

\begin{abstract}
Severe cerebral contusion is often associated with nonhemorrhagic mass effect that progresses rapidly within 12 to 48 hours posttrauma. The mechanisms underlying such a rapid progression of mass effect cannot be fully explained by classic concepts of vasogenic and cytotoxic brain edema. Data from previous clinical trials, including diffusion-weighted magnetic resonance imaging studies, have indicated that cells in the central (core) area of the contusion undergo shrinkage, disintegration, and homogenization, whereas cellular swelling is located predominately in the peripheral (rim) area during this period. The authors hypothesized that high osmolality within the contused brain tissue generates an osmotic potential across the central and peripheral areas or causes blood to accumulate a large amount of water. To elucidate the role of tissue osmolality in contusion edema, they investigated changes in tissue osmolality, specific gravity, and ion concentration in contused brain in both experimental and clinical settings. Their results demonstrated that cerebral contusion induced a rapid increase in tissue osmolality from a baseline level of $311.4 \pm 11.3$ to $402.8 \pm 15.1 \mathrm{mOsm}$ at 12 hours posttrauma $(\mathrm{p}<0.0001)$. Specific gravity in tissue significantly decreased from $1.0425 \pm 0.0026$ to $1.0308 \pm 0.0028(\mathrm{p}<0.01)$, reflecting water accumulation in contused tissue. The total ionic concentration $\left[\mathrm{Na}^{+}\right]+\left[\mathrm{K}^{+}\right]+\left[\mathrm{Cl}^{-}\right]$did not change significantly at any time point. Inorganic ions do not primarily contribute to this elevation in osmolality, suggesting that the increase in colloid osmotic pressure through the metabolic production of osmoles or the release of idiogenic osmoles can be a main cause of contusion edema.
\end{abstract}

KeY WoRds - brain edema - cerebral contusion - ion concentration • tissue osmolality - traumatic brain injury

$\mathrm{C}$ EREBRAL CONTUSION in the clinical context involves two types of brain edema. One is the early massive edema that occurs within 12 to 48 hours posttrauma, which creates strong mass effect resulting in progressive elevation in ICP and clinical deterioration. ${ }^{18}$ The other is delayed pericontusion edema, which on T2weighted MR imaging is typically seen in the white matter adjacent to the cerebral contusion several days posttrauma. ${ }^{19}$ This type of edema rarely causes ICP elevation leading to deterioration and death.

Data from previous clinical studies ${ }^{15,17-20}$ involving diffusion-weighted MR imaging have suggested that a large amount of edema fluid accumulates in necrotic brain tissue within the central area of contusion, which contributes to massive edema within 24 hours posttrauma. The rapid formation of mass effect is a prominent feature of cerebral contusion, ${ }^{18,20}$ which is not seen in other pathological conditions associated with brain edema, including cerebral ischemia, tumor, and infectious diseases.

Authors of most previous studies have proposed that

Abbreviations used in this paper: ICP = intracranial pressure; $\mathrm{MR}=$ magnetic resonance; $\mathrm{TBI}=$ traumatic brain injury. increased cerebrovascular permeability and subsequent vasogenic edema are the major causes of the nonhemorrhagic mass effect due to contusions. . $18,26,29$ However, results of recent studies using MR imaging have demonstrated that vasogenic edema does not develop within 24 hours posttrauma but instead arises 48 hours after trauma, predominantly in the white matter surrounding the contu-

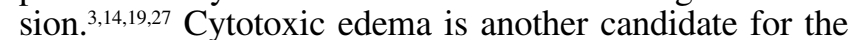
cause of mass effect in contusion, given that an ischemic condition is often induced by TBI. ${ }^{1,24,35}$ However, MR imaging data have demonstrated that although cytotoxic edema occurs soon after injury, it is not severe enough to induce prominent mass effect early after trauma. ${ }^{15}$ Mechanisms other than those of vasogenic and cytotoxic origins should be considered to cause the mass effect from cerebral contusion seen within 24 hours after injury.

It has been demonstrated that cerebral ischemia induces an elevation in tissue osmolality, which can lead to edema formation in the brain. ., $, 11,13,32$ It remains unclear whether or not this is the case in TBI. In the central area of contusion, the cellular elements-both neurons and glia-uniformly undergo disintegration and homogenization as the primary consequence of mechanical injury, even early 
after injury. ${ }^{8}$ This process can create a pathophysiological condition in which tissue osmolality increases rapidly in the core of the contusion and attracts a large amount of water within the necrotic tissue.

An increase in tissue ion concentration resulting from an $\mathrm{Na}^{+}$shift from blood has been regarded as a major factor responsible for elevating tissue osmolality in the ischemic brain. ${ }^{12,21,23,28}$ The increase in vascular permeability can also induce leakage of large molecules from plasma, resulting in elevated oncotic pressure in injured tissue. ${ }^{28}$ It is important to elucidate the mechanisms underlying TBI-induced hyperosmolality, because the prevention of increased osmolality can provide a new approach in the treatment of severe brain injury; however, the mechanisms have not yet been fully understood.

In the present study, we attempted to elucidate the role of tissue osmolality and ion concentrations in contusioninduced edema formation in both clinical and experimental settings. In our clinical investigations, the tissue osmolality of contused brain was determined in surgical specimens obtained from the contusion necrotomy. In our experimental study, the changes in tissue osmolality and water and ion contents following cerebral contusion were examined in a cortical contusion model in rats. We also sought to elucidate whether or not blood supply and/or enzymatic activation are involved in tissue osmolality elevation as well as the effects of brain cooling on osmolality elevation in a decapitation model in rats.

\section{Materials and Methods}

\section{Clinical Investigation}

This study was approved by the committee for clinical trial and research at Nihon University School of Medicine.

Brain tissue osmolality was determined in eight patients with cerebral contusion, who had medically uncontrollable elevated ICP and had undergone surgical removal of contusion necrosis for the purpose of internal decompression. Before removing contused brain, three small pieces of brain tissue approximately 3 to $5 \mathrm{~mm}$ in diameter were sampled from the central (core) and peripheral (rim) areas of the contusion. Immediately after sampling, brain tissue osmolality was determined using a vapor pressure osmometer (VPO 5500, Wescor, Inc.). ${ }^{33}$ The measurements were made in triplicate, and the values were averaged to obtain the representative osmolality in each case.

To determine the normal level of human brain tissue osmolality, similar sized pieces of healthy brain tissue were sampled (three pieces per case) from the surgical margins during lobectomy surgery in four patients with glioma.

\section{Experimental Investigation}

This study was approved by the Animal Care Committee of Nihon University School of Medicine.

\section{Cortical Contusion Model}

Surgical Preparation. Young Wistar rats weighing 250 to $300 \mathrm{~g}$ were anesthetized using a mixture of $33 \%$ oxygen, $66 \%$ nitrous oxide, and $1 \%$ halothane. The animals were mounted in a stereotactic frame in the prone position, and a 6-mm-diameter craniectomy was performed over the parietal cortex. Cerebral contusion, centered $2.5 \mathrm{~mm}$ pos- terior to the bregma and $3.0 \mathrm{~mm}$ from the midline, was induced using a controlled cortical impact device (diameter of injury tip $5 \mathrm{~mm}$, piston velocity $6 \mathrm{~m} /$ second, and penetration depth $3 \mathrm{~mm}){ }^{7,10}$ During the entire surgical procedure, the rectal temperature of each animal was maintained at $37^{\circ}$ to $38^{\circ} \mathrm{C}$ with a heating blanket.

Evaluation of Tissue Osmolality and Brain Edema. At 30 minutes and $1,3,6$, and 12 hours after injury induction, the animals (five animals for each time period, for a total of 25 animals) were killed, and small samples of brain tissue approximately $3 \mathrm{~mm}$ in diameter were taken from the central area of the contusion to determine tissue osmolality by using a vapor pressure osmometer.

In another group of animals, the severity of brain edema was evaluated at the same time points (five animals for each time period, for a total of 25 animals) by using the specific gravity method. ${ }^{26}$

Baseline levels of tissue osmolality and specific gravity were determined in sham-operated animals (five animals for each parameter, for a total of 10 rats), which underwent the same surgical procedure except for the induction of contusion.

Evaluation of the Brain Tissue Ion Contents. At 30 minutes and 6 and 12 hours after injury induction, a small sample of brain tissue (five animals for each time period, for a total of 15 animals) approximately $5 \mathrm{~mm}$ in diameter was taken from the center of the contusion. The wet weight of the tissue was precisely measured using a chemical balance, and the dry weight was measured after drying the brain tissue in an oven at $105^{\circ} \mathrm{C}$ for 24 hours. The dried brain tissue was immersed in deionized pure water, and the materials were filtered through a micropore membrane. The supernatant concentrations of $\mathrm{Na}^{+}, \mathrm{K}^{+}$, and $\mathrm{Cl}^{-}$ were determined with ion chromatography analysis and were converted into concentrations in the brain tissue (mmol/kg wet tissue). Baseline levels of ion contents were determined in the sham-operated animals (five rats).

Decapitation Model. Seventy-two young Wistar rats weighing 250 to $300 \mathrm{~g}$ were deeply anesthetized and decapitated to induce whole brain ischemia with complete disruption of the blood supply. The heads of the animals were wrapped with plastic film to avoid loss of water due to evaporation and were stored at $37^{\circ}, 20^{\circ}$, or $4^{\circ} \mathrm{C}$. At 0 , $0.5,1,3,6$, and 12 hours after decapitation, the brain was removed, and tissue osmolality was determined using a vapor pressure osmometer, as described previously.

\section{Statistical Analysis}

The statistical significance of the results was evaluated using the unpaired $\mathrm{t}$-test or Pearson correlation coefficient test. A probability value less than 0.05 was considered significant.

\section{Results}

\section{Clinical Investigations}

The tissue osmolality in healthy brain accessed during glioma surgery was $309.3 \pm 3.6$ mOsm (means \pm standard deviation). In cerebral contusion, brain tissue osmolality was $371.9 \pm 16.1 \mathrm{mOsm}$ in the central area and 

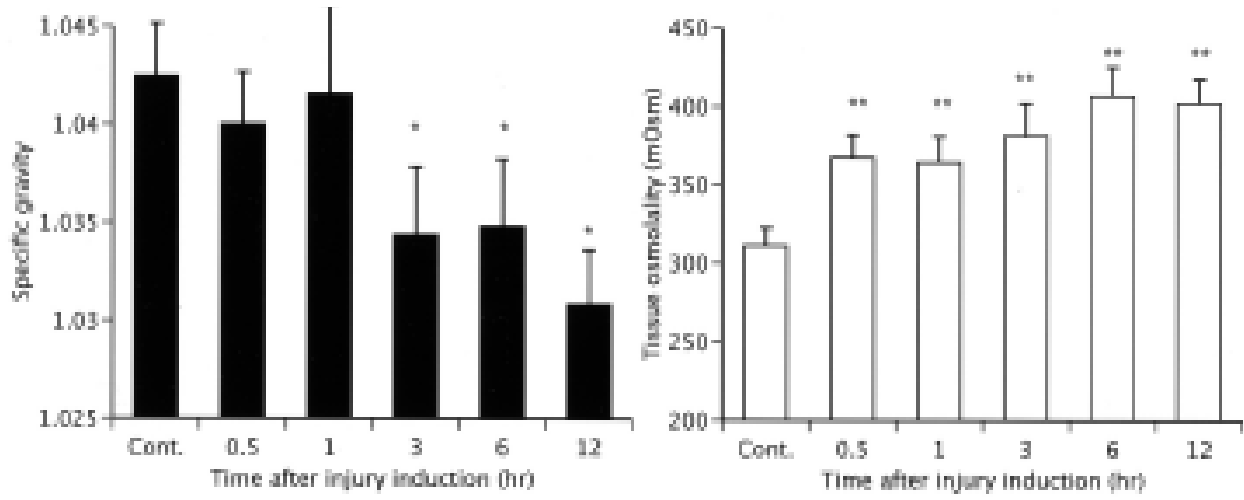

FIG. 1. Left: Bar graph depicting the changes in tissue specific gravity following cerebral contusion in a controlled cortical impact model in rats. The tissue specific gravity was significantly decreased at 3,6, and 12 hours posttrauma, representing progressive formation of brain edema. Right: Bar graph illustrating the rapid increase in tissue osmolality and subsequent plateau over $400 \mathrm{mOsm}$ at 6 hours posttrauma, which was approximately $100 \mathrm{mOsm}$ greater than the normal levels. Cont $=$ control values in sham-operated animals. $* \mathrm{p}<0.05 ; * * \mathrm{p}<0.01$.

$350.5 \pm 14.5 \mathrm{mOsm}$ in the peripheral area, values significantly higher than those in healthy brain $(\mathrm{p}=0.00002$ and $\mathrm{p}=0.00027$, respectively; Table 1$)$. Surgical procedures for contusion necrotomy were performed in patients 8 to 40 hours posttrauma (13.5 \pm 9.8 hours). The patients with later timing of surgery tended to have higher levels of contusion tissue osmolality; however, the correlation was not statistically significant ( $p=0.069$ in the central area and $\mathrm{p}=0.239$ in the peripheral area).

\section{Experimental Investigations}

Tissue Osmolality and Specific Gravity. Baseline levels of osmolality and specific gravity in contused tissue in sham-operated animals were $311.4 \pm 11.3 \mathrm{mmol} / \mathrm{kg}$ and $1.0425 \pm 0.0026$, respectively. Cerebral contusion induced a rapid decrease in tissue specific gravity to $1.0344 \pm 0.0035(\mathrm{p}=0.0031)$ at 3 hours posttrauma and $1.0308 \pm 0.0028(\mathrm{p}=0.00014)$ at 12 hours after injury (Fig. 1), reflecting water accumulation in contused brain. ${ }^{26}$ Simultaneously, tissue osmolality rose rapidly to $367.5 \pm$ $14.6 \mathrm{mmol} / \mathrm{kg}(\mathrm{p}=0.0001)$ at 0.5 hour and slowly thereafter to $402.8 \pm 15.1 \mathrm{mmol} / \mathrm{kg}(\mathrm{p}=0.00001)$ at 12 hours posttrauma.

Ion Concentrations. The tissue concentration of $\mathrm{Na}^{+}$ increased from a baseline level of $46.5 \pm 6.6$ to $53.7 \pm$ $0.6 \mathrm{mmol} / \mathrm{kg}$ at 0.5 hour $(\mathrm{p}=0.072)$ and to $74.2 \pm 18.4$ $\mathrm{mmol} / \mathrm{kg}$ at 12 hours $(\mathrm{p}=0.025$; Fig. 2$)$. The $\mathrm{K}^{+}$content showed a tendency to decrease from a baseline level of $92.7 \pm 11.9$ to $71.1 \pm 21.3 \mathrm{mmol} / \mathrm{kg}$ at 12 hours posttrauma $(p=0.083)$, but this change was not statistically

TABLE 1

Tissue osmolality in cerebral contusion*

\begin{tabular}{lcc}
\hline \hline \multicolumn{1}{c}{ Brain Tissue } & Osmolality (mOsm) & $\mathrm{p}$ Value \\
\hline control & $309.3 \pm 3.6$ & $\mathrm{NA}$ \\
central area of contusion & $371.9 \pm 16.1$ & 0.00002 \\
peripheral area of contusion & $347.5 \pm 12.9$ & 0.00027 \\
\hline
\end{tabular}

$* \mathrm{NA}=$ not applicable. significant. The $\mathrm{Cl}^{-}$contents were $43.7 \pm 11.2 \mathrm{mmol} / \mathrm{kg}$ at baseline and $51.2 \pm 18.6 \mathrm{mmol} / \mathrm{kg}$ at 12 hours after injury $(p=0.46)$, showing no significant differences at any time points. Eventually, the combined concentration of $\mathrm{Na}^{+}, \mathrm{K}^{+}$, and $\mathrm{Cl}^{-}$was slightly increased from a baseline level of $182.9 \pm 29.9$ to $186.4 \pm 20.8 \mathrm{mmol} / \mathrm{kg}$ at 0.5 hour $(\mathrm{p}=$ 0.79 ) and to $196.5 \pm 43.1 \mathrm{mmol} / \mathrm{kg}$ at 12 hours posttrauma $(p=0.55)$; however, the changes were not statistically significant.

Osmolality Changes in the Decapitation Model. Decapitation induced a rapid increase in brain tissue osmolality from a baseline level of $312.4 \pm 5.32$ to $450.7 \pm 11.5$ mOsm at 24 hours posttrauma under the $37^{\circ} \mathrm{C}$ condition (p $=0.0000006)$. Such a large osmolality increase was significantly attenuated by lowered brain temperature into $409.9 \pm 12.8 \mathrm{mOsm}$ at $20^{\circ} \mathrm{C}(\mathrm{p}=0.00074)$ and $354.5 \pm$ $9.7 \mathrm{mOsm}$ at $4^{\circ} \mathrm{C}(\mathrm{p}=0.00000057)$, at 24 hours posttrauma (Fig. 3).

\section{Discussion}

Data in the present study demonstrated that cerebral contusion induced a significant elevation in brain tissue osmolality and subsequent water accumulation in the area of contusion, in both experimental and clinical settings. Although the tissue concentration of $\mathrm{Na}^{+}$slightly increased, the total concentrations of ions $\left[\mathrm{Na}^{+}\right],\left[\mathrm{K}^{+}\right]$, and $\left[\mathrm{Cl}^{-}\right]$were not significantly altered by the injury, indicating that changes in tissue ion contents are not a major cause of the elevation in osmolality after cerebral contusion. Brain tissue osmolality was also increased by decapitation, and this increase was significantly attenuated by brain cooling, suggesting that the injury-induced osmolality elevation is a phenomenon irrelevant to blood supply but is dependent on brain temperature.

Authors of several experimental studies have revealed that in cerebral ischemia the osmolality of brain tissue was elevated concomitantly with edema formation soon after ischemia induction..$^{2,9,11,13,32}$ Hatashita and colleagues ${ }^{11}$ demonstrated that, following the induction of middle cerebral artery occlusion, water content in ischemic brain 

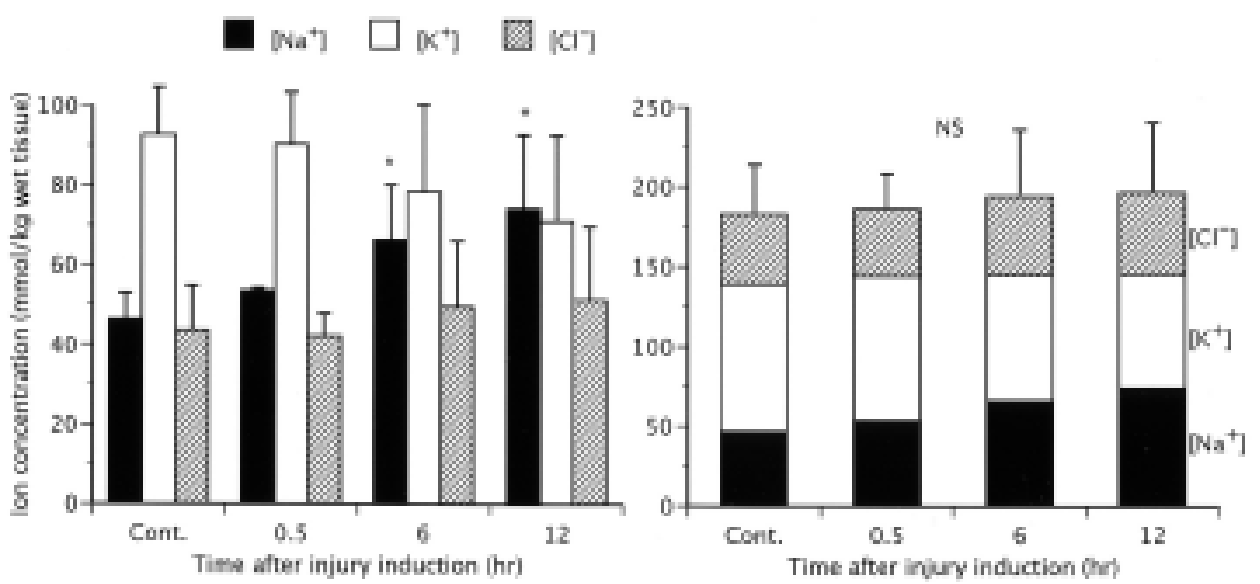

FIG. 2. Left: Bar graph showing changes in tissue contents of $\mathrm{Na}^{+}, \mathrm{K}^{+}$, and $\mathrm{Cl}^{-}$following cerebral contusion. The $\mathrm{Na}^{+}$ concentration was significantly increased at 6 and 12 hours posttrauma $(\mathrm{p}=0.025)$. The $\mathrm{K}^{+}$contents tended to decrease, but there was no significant difference compared with the baseline level $(\mathrm{p}=0.083)$. The $\mathrm{Cl}^{-}$contents showed no significant changes $(\mathrm{p}=0.46)$. ${ }^{*} \mathrm{p}<0.05$. Right: Bar graph revealing the combined concentration of $\mathrm{Na}^{+}, \mathrm{K}^{+}$, and $\mathrm{Cl}^{-}$following cerebral contusion. No significant changes were evident at any time points $(p=0.55)$, indicating that alterations in inorganic ion contents were not a major cause of the increase in tissue osmolality in contused tissue.

increased progressively over 24 hours, whereas brain tissue osmolality increased until 6 hours and returned to baseline within 12 hours postischemia. They concluded that an osmotic pressure gradient can contribute to edema formation only during the early stage of cerebral ischemia. In the present study we showed that tissue osmolality in the cerebral contusion rapidly increases, reaches a plateau level at 6 hours posttrauma, and remains high at 12 hours posttrauma, suggesting that increases in tissue osmolality are more prominent in contusion than in focal ischemia.

Cerebral contusion increased tissue osmolality from $311.4 \pm 11.3 \mathrm{mmol} / \mathrm{kg}$ at baseline to $402.8 \pm 15.1$ $\mathrm{mmol} / \mathrm{kg}$ at 12 hours posttrauma, representing a 91.5 mOsm increase in the experimental study, and from 309.3 \pm 3.6 to $371.9 \pm 16.1 \mathrm{mOsm}$, representing a $62.6-\mathrm{mOsm}$ increase in the clinical investigation. When such high tissue osmolality is facing the capillary wall, there can be no doubt that a large osmotic potential is produced and that large amounts of water continue to shift into contused brain from the blood, provided that blood supply is maintained. ${ }^{5,35}$ Indeed, our present data demonstrated massive water accumulation in contused tissue concomitant with the elevation in tissue osmolality.

In previous ischemia studies, increases in tissue ion concentrations, especially $\mathrm{Na}^{+}$, have been proposed as a major cause of elevated tissue osmolality. ${ }^{12,23,28}$ Results in the present study showed that contusion induced an increase in the tissue $\mathrm{Na}^{+}$concentration from $46.5 \pm 6.6$ $\mathrm{mmol} / \mathrm{kg}$ at baseline to $74.2 \pm 18.4 \mathrm{mmol} / \mathrm{kg}$ at 12 hours posttrauma $(\mathrm{p}=0.025)$. This $27.7-\mathrm{mmol} / \mathrm{kg}$ increase in the $\mathrm{Na}^{+}$concentration, however, cannot explain the 91.5$\mathrm{mmol} / \mathrm{kg}$ increase in tissue osmolality. Furthermore, the $\mathrm{K}^{+}$concentration in tissue was decreased by injury induction, from $92.7 \pm 11.9$ to $71.1 \pm 21.3 \mathrm{mmol} / \mathrm{kg}$, and the $\mathrm{Cl}^{-}$concentration showed no significant changes; therefore, the combined concentration of $\mathrm{Na}^{+}, \mathrm{K}^{+}$, and $\mathrm{Cl}^{-}$, the major ions influencing tissue osmolality, was not significantly altered following contusion (182.9 \pm 29.9 $\mathrm{mmol} / \mathrm{kg}$ compared with $196.5 \pm 43.1 \mathrm{mmol} / \mathrm{kg}$, baseline compared with 12 hours posttrauma, respectively; $\mathrm{p}=$ 0.55 ). These findings suggest that changes in inorganic ion contents are not a major cause of tissue osmolality increases in cerebral contusion.

The increase in $\mathrm{Na}^{+}$and decrease in $\mathrm{K}^{+}$content could be caused, at least in part, by diffusion migration due to an ion concentration gradient between contused brain tissue and extracellular fluid surrounding the contusion. Cerebral contusion induces rapid disruption of the cell membrane, resulting in homogenization of intra- and ex-

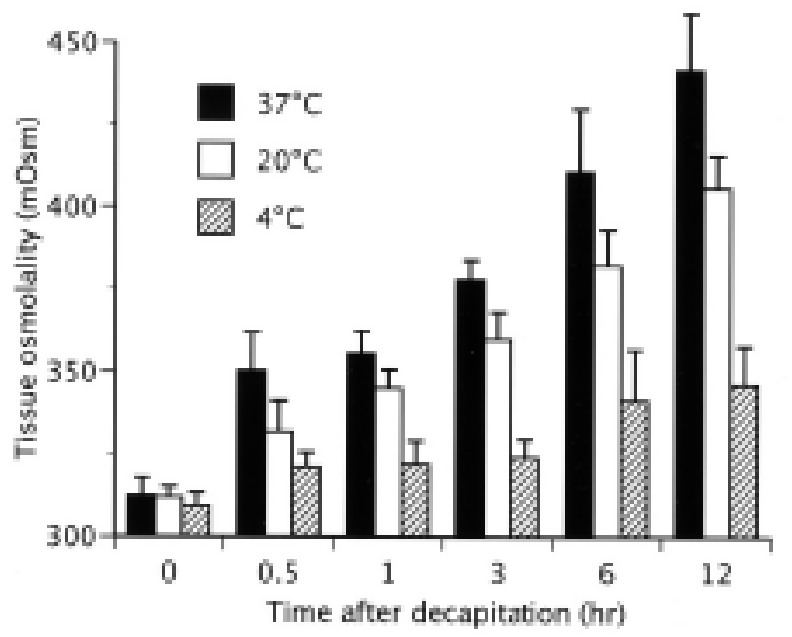

Fig. 3. Bar graph demonstrating changes in brain tissue osmolality in the decapitation model in rats with various brain temperatures $\left(37^{\circ}, 20^{\circ}\right.$, and $\left.4^{\circ} \mathrm{C}\right)$. Total brain ischemia caused by decapitation induced a marked elevation in osmolality to $450.7 \pm 11.5$ mOsm at 12 hours posttrauma $(p=0.0000006)$ in the condition of $37^{\circ} \mathrm{C}$. Such a large osmolality increase was significantly attenuated by lowered brain temperature at $20^{\circ}$ and $4^{\circ} \mathrm{C}(\mathrm{p}=0.0007$ and $\mathrm{p}=0.0000006$, respectively). 


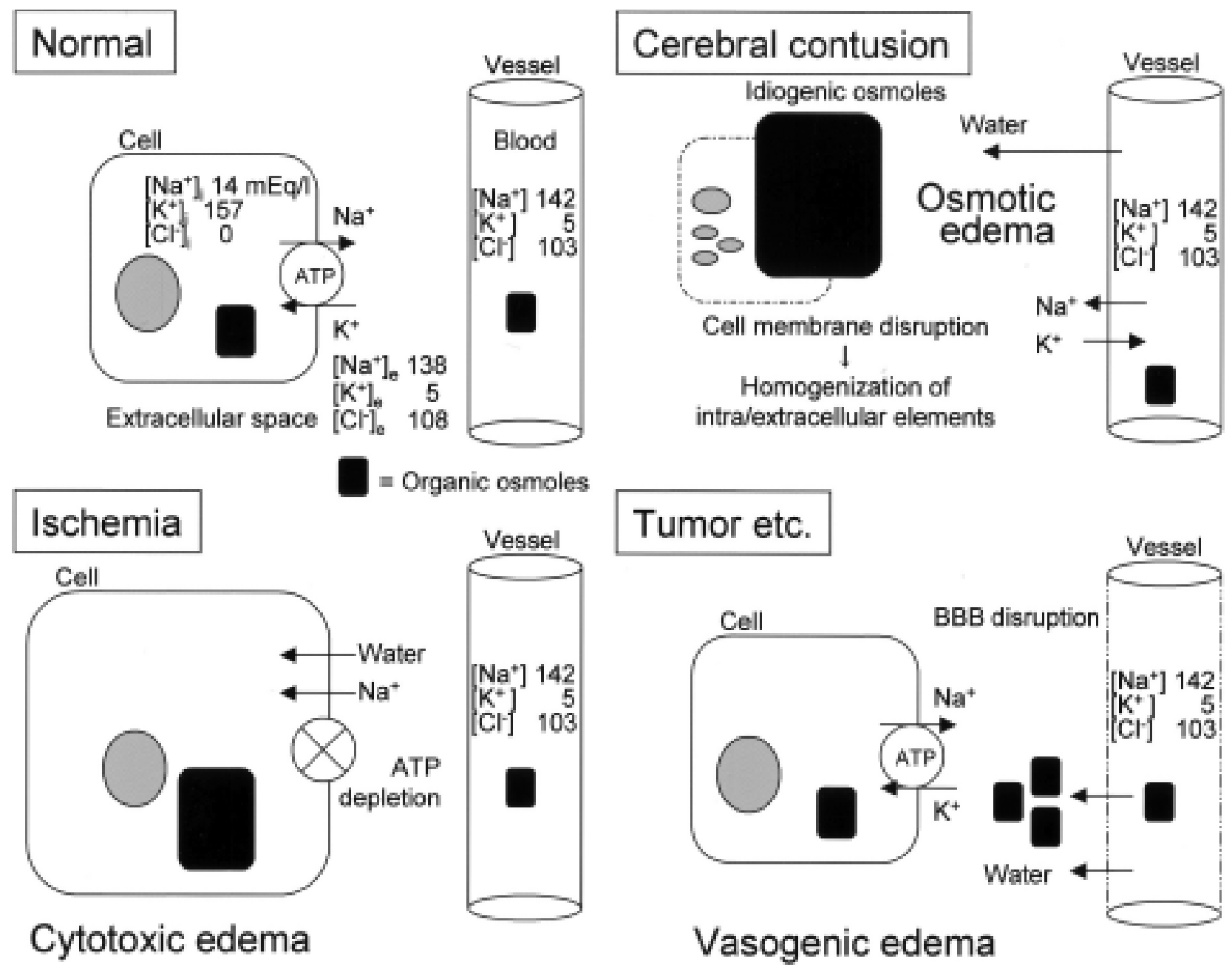

FIG. 4. Schematic showing the concentration distributions of organic and inorganic osmoles, which constitute tissue osmolality in normal brain (upper left), and in pathological conditions such as cerebral contusion (upper right), ischemia (lower left), and tumor (lower right). Ischemia induces energy depletion and ion pump failure, resulting in cellular swelling, that is, cytotoxic edema. Brain tumors, infectious diseases, or other pathological conditions disrupt vascular wall integrity and increase vascular permeability, leading to leakage of large molecules from plasma to the extracellular space and subsequent vasogenic edema. In contused brain, the formation of idiogenic osmoles can produce osmotic potential and attract a large amount of water from the blood or surrounding extracellular space, resulting in contusion edema with mass effect. ATP = adenosine triphosphate; $\mathrm{BBB}=$ blood-brain barrier; $\left[\mathrm{Cl}^{-}\right]_{\mathrm{e}},\left[\mathrm{K}^{+}\right]_{\mathrm{e}}$, and $\left[\mathrm{Na}^{+}\right]_{\mathrm{e}}=$ extracellular concentration of $\mathrm{Cl}^{-}, \mathrm{K}^{+}$, and $\mathrm{Na}^{+} ; \mathrm{K}^{+} ;\left[\mathrm{Cl}^{-}\right]_{\mathrm{i}},\left[\mathrm{K}^{+}\right]_{\mathrm{i}}$, and $\left[\mathrm{Na}^{+}\right]_{\mathrm{i}}=$ intracellular concentrations of $\mathrm{Cl}^{-}, \mathrm{K}^{+}$, and $\mathrm{Na}^{+}$.

tracellular elements as the primary consequence of mechanical injury. ${ }^{8}$ This feature is unique to cerebral contusion and is not seen in the early phase of ischemic brain or other pathological conditions. As compared with extracellular levels, the intracellular $\mathrm{Na}^{+}$concentration is low, approximately $15 \mathrm{mEq} / \mathrm{L}$, and the intracellular $\mathrm{K}^{+}$concentration is high, approximately $155 \mathrm{mEq} / \mathrm{L}$ in the normal condition (Fig. 4). Therefore, homogenization due to contusion induces decreased extracellular $\mathrm{Na}^{+}$and increased $\mathrm{K}^{+}$, promoting the ion concentration difference from the surrounding extracellular fluid and blood. This process can cause ion migrations by diffusion, which is an $\mathrm{Na}^{+}$ influx into contused tissue and a $\mathrm{K}^{+}$efflux to surrounding extracellular space or blood, resulting in increased tissue concentrations of $\mathrm{Na}^{+}$and decreased $\mathrm{K}^{+}$in contused brain.

A possible cause of tissue osmolality elevation is an oncotic pressure increase resulting from disruption of the blood-brain barrier., $4,930,34$ Cerebral contusion can increase vascular permeability, leading to leakage of large molecules, such as albumin, from plasma to contused tissue. However, an immunohistochemical study of the postmortem brain from patients with contusion failed to reveal any plasma protein leakage around contused brain areas during this early period. ${ }^{31}$ Similarly, evaluations of vascular permeability using ${ }^{99}$ mechnetium pertechnetate singlephoton emission tomography ${ }^{5}$ or MR imaging with intravenous Gd-diethylenetriamine pentaacetic acid injection failed to reveal any evidence of increased vascular permeability within the area of contusion during the initial few days posttrauma. ${ }^{3,20,22}$ Results of a recent study with diffusion-weighted MR imaging also revealed that vasogenic edema resulting from blood-brain barrier disruption did 
not appear in contused brain in the early period (that is, within 24 hours posttrauma) but did appear after 24 to 48 hours, predominantly in white matter surrounding the contusion. ${ }^{14,19}$ These findings seem to contradict the widely held view that increased cerebrovascular permeability is responsible for the development of contusion edema, especially soon after contusion.

Data in the present study also clearly demonstrated that brain tissue osmolality significantly increased in the decapitation model. Decapitation completely interrupted blood supply to the brain; therefore, the tissue osmolality increase was never attributable to the transfer of molecules (for example, $\mathrm{Na}^{+}$ion, albumin, and so forth) from blood to brain tissue. In such a condition, a possible mechanism underlying the injury-induced hyperosmolality is the degradation of large molecular compounds into small molecules. Total ischemia by decapitation could induce cell autolysis via enzyme activation, leading to intracellular catabolism and resultant osmolality elevation. The increase in brain tissue osmolality was significantly attenuated by brain cooling $\left(20^{\circ}\right.$ and $\left.4^{\circ} \mathrm{C}\right)$, suggesting that enzymatic processes are closely involved in hyperosmolality following decapitation.

Concerning the origins of the increase in tissue osmolality in contused brain tissue, findings in the present study strongly suggested that contusion induces an accumulation of metabolic intermediate osmoles or formation of idiogenic osmoles, which are produced in the pathological processes of cellular metabolism and enzyme activation, such as catabolism of lipid or proteins, glycolysis, hydrolysis of adenosine 5'-triphosphate, DNA fragmentation, and so forth. ${ }^{6}$ It has been reported, for instance, that ischemic brain injury activates phospholipases, which catabolize injured cell membrane and result in the liberation of free fatty acids and their metabolites (for example, prostaglandin, thromboxanes, or leucotrienes). ${ }^{16}$ Such degradation processes of large molecules would increase the number of small molecules in the tissue, inducing an elevation in tissue osmolality. The rapid membrane disruption following cerebral contusion can also induce the efflux of intracellular idiogenic osmoles into the extracellular space, which can enhance the osmotic potential between blood and extracellular fluid, resulting in edema formation (Fig. 4).

Results of previous investigations have indicated that cellular swelling and vasogenic edema are important causes of the nonhemorrhagic mass effect in cerebral contusion. $1,3,5,18,20,24,25,27,29,35$ In addition to these causes, data in the present study showed that the contusion tissue itself has the potential to accumulate massive amounts of water as a result of the increase in tissue osmolality. Note that tissue osmolality of $380 \mathrm{mOsm}$ or greater can induce a condition resistant to hyperosmotic diuretic therapy. Surgical removal of the contusion necrosis area represents the most effective therapy currently available to control the elevated osmotic potential in patients with severe cerebral contusion..$^{15,17}$

\section{Conclusions}

Data in the present study revealed that 1) osmolality of the contused brain tissue increases rapidly; 2) contused brain tissue strongly attracts water; 3) an increase in osmolality is not caused by changes in inorganic ion contents; 4) blood supply is not essential to elevate tissue osmolality; and 5) an osmolality increase is temperature dependent, suggesting an increase in colloid osmotic pressure through the metabolic production of osmoles or release of idiogenic osmoles. It is inferred that the primary driving force of water accumulation into contused brain tissue can be an elevated organic osmotic potential resulting from contusion necrosis.

\section{References}

1. Alexander MJ, Martin NA, Khanna M, Caron M, Becker DP: Regional cerebral blood flow trends in head injured patients with focal contusions and cerebral edema. Acta Neurochir Suppl (Wien) 60:479-481, 1994

2. Bandaranayake NM, Nemoto EM, Stezoski SW: Rat brain osmolality during barbiturate anesthesia and global brain ischemia. Stroke 9:249-254, 1978

3. Barzó P, Marmarou A, Fatouros P, Corwin F, Dunbar J: Magnetic resonance imaging-monitored acute blood-brain barrier changes in experimental traumatic brain injury. $\mathbf{J}$ Neurosurg 85:1113-1121, 1996

4. Bothe HW, Bodsch W, Hossmann KA: Relationship between specific gravity, water content, and serum protein extravasation in various types of vasogenic brain edema. Acta Neuropathol 64:37-42, 1984

5. Bullock R, Statham J, Patterson D, Wyper D, Hadley D, Teasdale E: The time course of vasogenic oedema after focal human head injury-evidence from SPECT mapping of blood brain barrier defects. Acta Neurochir Suppl (Wien) 51:286-288, 1990

6. Chan PH, Fishman RA: Elevation of rat brain amino acids, ammonia and idiogenic osmoles induced by hyperosmolality. Brain Res 161:293-301, 1979

7. Dixon CE, Clifton GL, Lightall JW, Yaghmai AA, Hayes RL: A controlled cortical impact model of traumatic brain injury in the rat. J Neurosci Methods 39:253-262, 1991

8. Freytag E, Lindenberg R: Morphology of cortical contusions. AMA Arch Path 63:23-42, 1957

9. Gisselson L, Smith ML, Siesjo BK: Influence of preischemic hyperglycemia on osmolality and early postischemic edema in the rat brain. J Cereb Blood Flow Metab 12:809-816, 1992

10. Goodman JC, Cherian L, Bryan RM Jr, Robertson CS: Lateral cortical impact injury in rats: pathologic effects of varying cortical compression and impact velocity. J Neurotrauma 11:587-597, 1994

11. Hatashita S, Hoff JT, Salamat SM: Ischemic brain edema and the osmotic gradient between blood and brain. J Cereb Blood Flow Metab 8:552-559, 1988

12. Hossmann KA, Schuier FJ: Experimental brain infarcts in cats. I. Pathophysiological observations. Stroke 11:583-592, 1980

13. Hossmann KA, Takagi S: Osmolality of brain in cerebral ischemia. Exp Neurol 51:124-131, 1976

14. Ito J, Marmarou A, Barzó P, Fatouros P, Corwin F: Characterization of edema by diffusion-weighted imaging in experimental traumatic brain injury. J Neurosurg 84:97-103, 1996

15. Katayama Y, Kawamata T: Edema fluid accumulation within necrotic brain tissue as a cause of the mass effect of cerebral contusion in head trauma patient. Acta Neurochir Suppl 86: 323-327, 2003

16. Katayama Y, Kawamata T, Maeda T, Ishikawa K, Tsubokawa $\mathrm{T}$ : Inhibition of the early phase of free fatty acid liberation during cerebral ischemia by excitatory amino acid antagonist administered by microdialysis. Brain Res 635:331-334, 1994

17. Katayama $\mathrm{Y}$, Tsubokawa $\mathrm{T}$, Kinoshita K, Himi K: Intraparenchymal blood-fluid levels in traumatic intracerebral 
hematomas. Neuroradiology 34:381-383, 1992

18. Katayama Y, Tsubokawa T, Miyazaki S, Kawamata T, Yoshino A: Oedema fluid formation within contused brain tissue as a cause of medically uncontrollable elevation of intracranial pressure: the role of surgical therapy. Acta Neurochir Suppl 51:308-310, 1990

19. Kawamata T, Katayama Y, Aoyama N, Mori T: Heterogeneous mechanisms of early edema formation in cerebral contusion: diffusion MRI and ADC mapping study. Acta Neurochir Suppl 76:9-12, 2000

20. Kushi H, Katayama Y, Shibuya T, Tsubokawa T, Kuroha T: Gadolinium DTPA-enhanced magnetic resonance imaging of cerebral contusions. Acta Neurochir Suppl 60:472-474, 1994

21. Kwo S, Young W, Decrescito V: Spinal cord sodium, potassium, calcium, and water concentration changes in rats after graded contusion injury. J Neurotrauma 6:13-24, 1989

22. Lang DA, Hadley DM, Teasdale GM, Macpherson P, Teasdale E: Gadolinium DTPA enhanced magnetic resonance imaging in acute head injury. Acta Neurochir (Wien) 109:5-11, 1991

23. Lo WD, Betz AL, Schielke GP, Schielke GP, Hoff JT: Transport of sodium from blood to brain in ischemic brain edema. Stroke 18:150-157, 1987

24. Marmarou A: Pathophysiology of traumatic brain edema: current concepts. Acta Neurochir Suppl 86:7-10, 2003

25. Marmarou A, Maset AL, Ward JD, Choi S, Brooks D, Lutz HA, et al: Contribution of CSF and vascular factors to elevation of ICP in severely head-injured patients. J Neurosurg 66: 883-890, 1987

26. Marmarou A, Poll W, Shulman K, Bhagavan H: A simple gravimetric technique for measurement of cerebral edema. J Neurosurg 49:530-537, 1978

27. Marmarou A, Portella G, Barzo P, Signoretti S, Fatouros P,
Beaumont A, et al: Distinguishing between cellular and vasogenic edema in head injured patients with focal lesions using magnetic resonance imaging. Acta Neurochir Suppl 76: 349-351, 2000

28. Menzies SA, Betz AL, Hoff JT: Contributions of ions and albumin to the formation and resolution of ischemic brain edema. $\mathbf{J}$ Neurosurg 78:257-266, 1993

29. Sutton RL, Lescaudron L, Stein DG: Unilateral contusion injury in the rat: vascular disruption and temporal development of cortical necrosis. J Neurotrauma 10:135-149, 1993

30. Tanno H, Nockels RP, Pitts LH, Noble LJ: Breakdown of the blood-brain barrier after fluid percussive brain injury in the rat. Part 1: Distribution and time course of protein extravasation. J Neurotrauma 9:21-32, 1992

31. Todd NV, Graham DI: Blood-brain barrier damage in traumatic brain contusions. Acta Neurochir Suppl 51:296-299, 1990

32. Tomita M, Gotoh F, Sato T, Yamamoto M, Amano T, Tanahashi N, et al: Determination of the osmotic potential for swelling of cat brain in vitro. Exp Neurol 65:66-77, 1979

33. Tornheim PA: Use of a vapor pressure osmometer to measure brain osmolality. J Neurosci Methods 3:21-35, 1993

34. Tornheim, PA, Prioleau GR, McLaurin RL: Acute responses to experimental blunt head trauma. Topography of cerebral cortical edema. J Neurosurg 60:473-480, 1984

35. Unterberg AW, Stover J, Kress B, Kiening KL: Edema and brain trauma. Neuroscience 129:1021-109, 2004

Manuscript submitted February 15, 2007.

Accepted March 29, 2007.

Address reprint requests to: Tatsuro Kawamata, M.D., Department of Neurological Surgery, Nihon University School of Medicine, 30-1 Oyaguchi Kamimachi, Itabashi-ku, Tokyo 173-8610, 
Author Names, et al.

Japan. email: kawamata@med.nihon-u.ac.jp. 